\title{
Fuzzy Time Series Forecasting Based On K-Means Clustering
}

\author{
Zhiqiang Zhang \\ Department of Statistics \\ School of Economics \\ Xiamen University, \\ Xiamen, PR. China \\ e-mail: jsxzx06@xmu.edu.cn
}

\author{
Qiong Zhu \\ School of Mathematical Science \\ Xiamen University, \\ Xiamen, PR. China \\ e-mail: 516191479@qq.com
}

\begin{abstract}
Many forecasting models based on the concepts of Fuzzy time series have been proposed in the past decades. These models have been widely applied to various problem domains, especially in dealing with forecasting problems in which historical data are linguistic values. In this paper, we present a new fuzzy time series forecasting model, which uses the historical data as the universe of discourse and uses the K-means clustering algorithm to cluster the universe of discourse, then adjust the clusters into intervals. The proposed method is applied for forecasting University enrollment of Alabama. It is shown that the proposed model achieves a significant improvement in forecasting accuracy as compared to other fuzzy time series forecasting models.
\end{abstract}

Keywords - fuzzy time series; fuzzy sets; K-means; enrollments

\section{Introduction}

A drawback of traditional forecasting methods is that they can not deal with forecasting problems in which the historical data are represented by linguistic values. Using fuzzy time series to deal with forecasting problems can overcome this drawback. Song and Chissom were the pioneers of studying fuzzy time series models. The historical enrollment data of the University of Alabama were first adopted by Song and Chissom [1][2]. Because of its better performance in some kinds of forecasting problems, many researchers have proposed different fuzzy time series models in order to improve the forecasting accuracy. Chen [3] presented a simplified method of fuzzy time series forecasting of enrollments using the arithmetic operations rather than complicated max-min composition operations. Wang, Chen, and Lee [4] considered to use high-order time variant fuzzy time series model to deal with enrollment forecasting. Huarng [5] presented a heuristic model for fuzzy time series using heuristic knowledge to improve the forecast of enrollments. Jilani, Burney, Ardil [6] used a triangular function to define the fuzzy sets. In this paper, we present a new method to forecast enrollments based on kmean clustering techniques. First, we select the historical data as the universe of discourse. Then we present the k-mean clustering algorithm for clustering the data into different lengths of intervals. Based on the new obtained intervals, we can propose a new method to forecast the enrollment of the university of Alabama. The proposed model is easy for implementation and the forecasting is more accurate than the other fuzzy time series methods.

The rest of this paper is organized as follows. In Section 2, we briefly review the basic definitions of fuzzy time series models. In Section 3, we present a new method for handing forecasting problems based on k-means clustering techniques through the experiments of forecasting of the university of
Alabama. In Section 4, we make a comparison of the proposed forecasting model with existing methods. Finally, summary and conclusions will be drawn in Section 5 .

\section{FUZZY TIME SERIES}

In this section, we briefly review some basic concepts of fuzzy time series proposed by Song and Chissom [1][2], where the values of fuzzy time series are represented by fuzzy sets. Let $U$ be the universe of discourse, where $U=\left\{u_{1}, u_{2}, \cdots, u_{n}\right\}$. A fuzzy set $A$ in the universe of discourse $U$ can be represented by

$$
A=\frac{f_{A}\left(u_{1}\right)}{u_{1}}+\frac{f_{A}\left(u_{2}\right)}{u_{2}}+\cdots \frac{f_{A}\left(u_{n}\right)}{u_{n}}
$$

Where $f_{A}$ is the membership function of the fuzzy set $A$, $f_{A}: U \rightarrow[0,1], f_{A}\left(u_{i}\right)$ denotes the grade of the membership of $u_{i}$ in the fuzzy set $A$, and $1 \leq i \leq n$. Let $Y(t), t=0,1,2, \cdots$, is a subset of $R$, be the universe of discourse on which fuzzy sets $f_{i}(t), \quad i=1,2,3, \ldots$ are defined and $F(t)$ is the collection of $f_{i}(t)$, then $F(t)$ is called fuzzy time series on $Y(t)$. If there exists a fuzzy logical relationship $R(t-1, t)$ such that $F(t)=F(t-1) \otimes R(t-1, t)$, where both $F(t)$ and $F(t-1)$ are fuzzy sets and the symbol “ $\otimes$ " is the max-min composition operator, then $F(t)$ is called derived by $F(t-1)$, denoted by a fuzzy logical relationship shown as follows: $F(t-1) \rightarrow F(t)$. If $F(t-1)=A_{i}$ and $F(t)=A_{j}$, where $A_{i}$ and $A_{j}$ are fuzzy sets, then the fuzzy logical relationship between $F(t-1)$ and $F(t)$ can be represented by 
$A_{i} \rightarrow A_{j}$, where $A_{i}$ and $A_{j}$ are called current state and the next state of the fuzzy logical relationship, respectively.

\section{A New Method For Fuzzy Time Series Forecasting}

In this section, we present the stepwise procedure of the proposed method for fuzzy time series forecasting based on historical time series data and apply the proposed method to forecast the enrollments of the University of Alabama. TABLE 1 shows the historical enrollments data of the University of Alabama.

TABLE 1. HISTORICAL ENROLLMENTS OF UNIVERSITY OF ALABAMA

\begin{tabular}{|c|c|c|c|}
\hline Year & Actual enrollments & Year & Actual enrollments \\
\hline 1971 & 13055 & 1982 & 15433 \\
\hline 1972 & 13563 & 1983 & 15497 \\
\hline 1973 & 13867 & 1984 & 15145 \\
\hline 1974 & 14696 & 1985 & 15163 \\
\hline 1975 & 15460 & 1986 & 15984 \\
\hline 1976 & 15311 & 1987 & 16859 \\
\hline 1977 & 15603 & 1988 & 18150 \\
\hline 1978 & 15861 & 1989 & 18970 \\
\hline 1979 & 16807 & 1990 & 19328 \\
\hline 1980 & 16919 & 1991 & 19337 \\
\hline 1981 & 16388 & 1992 & 18876 \\
\hline
\end{tabular}

The proposed method and the experiment results are now presented as follows:

Step 1: Apply the K-means clustering algorithm to partition the historical time series data into 14 clusters and sort the data in clusters in an ascending sequence, the results are as follows:

$\{13055\},\{13563\},\{13867\},\{14696\},\{15145,15163\},\{15311,1$ $5433,15460,15497\},\{15603\},\{15861\},\{15984\},\{16388\},\{168$ $07,16859,16919\},\{18150\},\{18876,18970\},\{19328,19337\}$.

Step 2: Calculate the cluster center cluster_center $_{m}$ shown in TABLE 2 of each cluster cluster $_{m}$ as follows:

cluster_center $_{m}=\frac{\sum_{j=1}^{r} d_{j}}{r}$

Step 3: Adjust the clusters into intervals according to the follow rules. Assume that cluster_center ${ }_{m}$ and cluster_center ${ }_{m+1}$ are adjacent cluster centers, then the upper bound cluster_uBound ${ }_{m}$ of cluster $_{m}$ and the lower bound cluster_lBound $_{m+1}$ of cluster $_{m+1}$ shown in TABLE 2 can be calculated as follows:

$$
\begin{aligned}
& \text { cluster_uBound }_{m}=\frac{\text { cluster_center }_{m}+\text { cluster_center }_{m+1}}{2} \\
& \text { cluster_lBound }_{m+1}=\text { cluster_uBound }_{m}
\end{aligned}
$$

where $m=1,2, \cdots k-1$. Because there is no previous cluster before the first cluster and there is no next cluster after the last cluster, the lower bound cluster_lBound ${ }_{1}$ of the first cluster and the upper bound cluster_uBound ${ }_{k}$ of the last cluster can be calculated as follows:

$$
\begin{aligned}
& \text { cluster_uBound }_{k}=\text { cluster_center }_{k} \\
& +\left(\text { cluster_center }_{k}-\text { cluster_lBound }_{k}\right) \\
& \text { cluster_lBound }_{1}=\text { cluster_center }_{1} \\
& -\left(\text { cluster_uBound }_{1}-\text { cluster_center }_{1}\right)
\end{aligned}
$$

After applying the procedure, we can get the following intervals and calculate the middle value of the interval in TABLE 2,

$$
\begin{array}{ll}
u_{1}=[12801,13309) & u_{2}=[13309,13715) \\
u_{3}=[13715,14282) & u_{4}=[14282,14925) \\
u_{5}=[14925,15290) & u_{6}=[15290,15514) \\
u_{7}=[15514,15732) & u_{8}=[15732,15923) \\
u_{9}=[15923,16186) & u_{10}=[16186,16625) \\
u_{11}=[16625,17506) & u_{12}=[17506,18537) \\
u_{13}=[18537,19128) & u_{14}=[19128,19537]
\end{array}
$$

Step 4: Define each fuzzy set $X_{i}$ based on the intervals and the historical enrollments shown in TABLE 1, where fuzzy set $X_{i}$ denotes a linguistic value of the enrollments represented by a fuzzy set. As in [6], we use a triangular function to define the fuzzy sets $X_{i}$.

Step 5: Defuzzify the fuzzy data using the forecasting formula

The support of National Social Science Fund Project (11BTJ001), MOE Key Laboratory of Econometrics and Fujian Key Laboratory of Statistical Sciences are gratefully acknowledged. 


$$
t_{j}=\left\{\begin{array}{c}
\frac{1.5}{\frac{1}{a_{1}}+\frac{0.5}{a_{2}}}, \text { if }, j=1 \\
\frac{2}{\frac{0.5}{a_{j-1}}+\frac{1}{a_{j}}+\frac{0.5}{a_{j+1}}}, \text { if }, 2 \leq j \leq n-1 \\
\frac{1.5}{\frac{0.5}{a_{n-1}}+\frac{1}{a_{n}}}, \text { if }, j=n
\end{array}\right.
$$

TABLE 2. THE INTERVALS GENERATION PROCESS FROM THE CLUSTERS OF THE HISTORICAL ENROLLMENTS OF UNIVERSITY OF ALABAMA

\begin{tabular}{|c|l|l|l|l|c|}
\hline cluster & data & $\begin{array}{l}\text { cluster } \\
\text { center }\end{array}$ & $\begin{array}{l}\text { lower } \\
\text { bound }\end{array}$ & $\begin{array}{c}\text { upper } \\
\text { bound }\end{array}$ & $\begin{array}{c}\text { value } \\
\text { vale }\end{array}$ \\
\hline 1 & $\{13055\}$ & 13055 & 12801 & 13309 & 13055 \\
\hline 2 & $\{13563\}$ & 13563 & 13309 & 13715 & 13512 \\
\hline 3 & $\{13867\}$ & 13867 & 13715 & 14281.5 & 13998 \\
\hline 4 & $\{14696\}$ & 14696 & 14281.5 & 14925 & 14603.25 \\
\hline 5 & $\begin{array}{l}\{15145, \\
15163\}\end{array}$ & 15154 & 14925 & 15289.6 & 15107.3 \\
\hline 6 & $\begin{array}{l}\{15311, \\
15433, \\
15460, \\
15497\}\end{array}$ & 15425.25 & 15289.6 & 15514.1 & 15401.9 \\
\hline 7 & $\{15603\}$ & 15603 & 15514.1 & 15732 & 15623.1 \\
\hline 8 & $\{15861\}$ & 15861 & 15732 & 15922.5 & 15827.25 \\
\hline 9 & $\{15984\}$ & 15984 & 15922.5 & 16186 & 16054.3 \\
\hline 10 & $\{16388\}$ & 16388 & 16186 & 16624.85 & 16405.4 \\
\hline 11 & $\begin{array}{l}\{16807, \\
16859, \\
16919\}\end{array}$ & 16861.7 & 16624.85 & 17505.85 & 17065.4 \\
\hline 13 & $\begin{array}{l}\{18150\} \\
18970\}\end{array}$ & 18150 & 17505.85 & 18536.5 & 18021.2 \\
\hline 19337$\}$ & 19332.5 & 19127.8 & 19537.3 & 19332.6 \\
\hline
\end{tabular}

Where $a_{j-1}, a_{j}, a_{j+1}$ are the midpoints of the fuzzy intervals $X_{j-1}, X_{j}, X_{j+1}$ respectively. $t_{j}$ yields the predicted enrollment.

The forecasted enrollment is provided in TABLE3.

TABLE3. FORECASTING OF THE PROPOSED MODEL

\begin{tabular}{|c|c|c|c|c|c|c|c|}
\hline Year & $\begin{array}{c}\text { Enroll- } \\
\text { ments }\end{array}$ & $\begin{array}{c}\text { Fuzzy } \\
\text { set }\end{array}$ & $\begin{array}{c}\text { Fore- } \\
\text { cast }\end{array}$ & Year & $\begin{array}{c}\text { Enroll- } \\
\text { ments }\end{array}$ & $\begin{array}{c}\text { Fuzzy } \\
\text { set }\end{array}$ & $\begin{array}{c}\text { Fore- } \\
\text { cast }\end{array}$ \\
\hline 1971 & 13055 & $\mathrm{X}_{1}$ & 13204 & 1982 & 15433 & $\mathrm{X}_{6}$ & 15381 \\
\hline 1972 & 13563 & $\mathrm{X}_{2}$ & 13511 & 1983 & 15497 & $\mathrm{X}_{6}$ & 15381 \\
\hline 1973 & 13867 & $\mathrm{X}_{3}$ & 14017 & 1984 & 15145 & $\mathrm{X}_{5}$ & 15049 \\
\hline 1974 & 14696 & $\mathrm{X}_{4}$ & 14567 & 1985 & 15163 & $\mathrm{X}_{5}$ & 15049 \\
\hline 1975 & 15460 & $\mathrm{X}_{6}$ & 15381 & 1986 & 15984 & $\mathrm{X}_{9}$ & 16082 \\
\hline
\end{tabular}

\begin{tabular}{|c|c|c|c|c|c|c|c|}
\hline 1976 & 15311 & $\mathrm{X}_{6}$ & 15381 & 1987 & 16859 & $\mathrm{X}_{11}$ & 17120 \\
\hline 1977 & 15603 & $\mathrm{X}_{7}$ & 15617 & 1988 & 18150 & $\mathrm{X}_{12}$ & 17963 \\
\hline 1978 & 15861 & $\mathrm{X}_{8}$ & 15832 & 1989 & 18970 & $\mathrm{X}_{13}$ & 18743 \\
\hline 1979 & 16807 & $\mathrm{X}_{11}$ & 17120 & 1990 & 19328 & $\mathrm{X}_{14}$ & 19163 \\
\hline 1980 & 16919 & $\mathrm{X}_{11}$ & 17120 & 1991 & 19337 & $\mathrm{X}_{14}$ & 19163 \\
\hline 1981 & 16388 & $\mathrm{X}_{10}$ & 16474 & 1992 & 18876 & $\mathrm{X}_{13}$ & 18743 \\
\hline
\end{tabular}

\section{A Comparsion of Different Forecasting Methods}

In this section, a comparison of accuracy in forecasted values of our proposed model with other models is made on the basis of mean square error (MSE) of forecasted values which are computed as:

MSE $=\frac{\sum_{i=1}^{n}\left(\text { actual }_{\text {value }}-\text { forecasted }_{\text {_value }}\right)^{2}}{n}$

where $\mathrm{n}$ is the number of years needed to forecast the enrollments. The comparison of MSE of the proposed method with different methods are shown in TABLE 4 and TABLE 5.

TABLE 4. A COMPARISON OF MES OF THE PROPOSED METHOD WITH THE EXISTING METHODS

\begin{tabular}{|c|c|c|c|c|c|}
\hline Year & $\begin{array}{c}\text { Enroll- } \\
\text { ment }\end{array}$ & $\begin{array}{c}\text { Song } \\
{[\mathbf{1}]}\end{array}$ & $\begin{array}{c}\text { Song } \\
{[\mathbf{2}]}\end{array}$ & $\begin{array}{c}\text { Chen } \\
{[\mathbf{3}]}\end{array}$ & $\begin{array}{c}\text { Wang } \\
{[\mathbf{4}]}\end{array}$ \\
\hline 1971 & 13055 & - & - & - & - \\
\hline 1972 & 13563 & 14000 & - & 14000 & - \\
\hline 1973 & 13867 & 14000 & - & 14000 & - \\
\hline 1974 & 14696 & 14000 & - & 14000 & - \\
\hline 1975 & 15460 & 15500 & 14700 & 15500 & - \\
\hline 1976 & 15311 & 16000 & 14800 & 16000 & 16260 \\
\hline 1977 & 15603 & 16000 & 15400 & 16000 & 15511 \\
\hline 1978 & 15861 & 16000 & 15500 & 16000 & 16003 \\
\hline 1979 & 16807 & 16000 & 15500 & 16000 & 16261 \\
\hline 1980 & 16919 & 16813 & 16800 & 16833 & 17407 \\
\hline 1981 & 16388 & 16813 & 16200 & 16833 & 17119 \\
\hline 1982 & 15433 & 16789 & 16400 & 16833 & 16188 \\
\hline 1983 & 15497 & 16000 & 16800 & 16000 & 14833 \\
\hline 1984 & 15145 & 16000 & 16400 & 16000 & 15497 \\
\hline 1985 & 15163 & 16000 & 15500 & 16000 & 14745 \\
\hline 1986 & 15984 & 16000 & 15500 & 16000 & 15163 \\
\hline 1987 & 16859 & 16000 & 15500 & 16000 & 16384 \\
\hline 1988 & 18150 & 16813 & 16800 & 16833 & 17659 \\
\hline 1989 & 18970 & 19000 & 19300 & 19000 & 19150 \\
\hline 1990 & 19328 & 19000 & 17800 & 19000 & 19770 \\
\hline 1991 & 19337 & 19000 & 19300 & 19000 & 19928 \\
\hline 1992 & 18876 & - & 19600 & 19000 & 15837 \\
\hline
\end{tabular}




\begin{tabular}{|l|l|l|l|l|l|}
\hline MSE & - & 775687 & 407507 & 321418 & 226611 \\
\hline
\end{tabular}

\section{Conclution}

The study proposed a new method for fuzzy time series forecasting with high accuracy. The K-means algorithm of the proposed method is simple and can be implemented easily by using mathematic software-Matlab. The method has been implemented on the historical time series data of enrollments of University of Alabama to have a comparative study with the existing methods. From Table 4 and Table 5 we can see that the proposed method has a higher forecasting accuracy rate than the methods presented before.

TABLE 5. A COMPARISON OF MES OF THE PROPOSED METHOD WITH THE EXISTING METHODS

\begin{tabular}{|c|c|c|c|c|}
\hline Year & $\begin{array}{c}\text { Enroll- } \\
\text { ment }\end{array}$ & $\begin{array}{c}\text { Huarng } \\
{[5]}\end{array}$ & $\begin{array}{c}\text { Jilani } \\
{[6]}\end{array}$ & $\begin{array}{c}\text { Our } \\
\text { Method }\end{array}$ \\
\hline 1971 & 13055 & - & 13579 & 13204 \\
\hline 1972 & 13563 & 14000 & 13798 & 13511 \\
\hline 1973 & 13867 & 14000 & 13798 & 14017 \\
\hline 1974 & 14696 & 14000 & 14452 & 14567 \\
\hline 1975 & 15460 & 15500 & 15373 & 15381 \\
\hline 1976 & 15311 & 15500 & 15373 & 15381 \\
\hline 1977 & 15603 & 16000 & 15623 & 15617 \\
\hline 1978 & 15861 & 16000 & 15883 & 15832 \\
\hline 1979 & 16807 & 16000 & 17079 & 17120 \\
\hline 1980 & 16919 & 17500 & 17079 & 17120 \\
\hline 1981 & 16388 & 16000 & 16497 & 16474 \\
\hline 1982 & 15433 & 16000 & 15737 & 15381 \\
\hline 1983 & 15497 & 16000 & 15737 & 15381 \\
\hline 1984 & 15145 & 15500 & 15024 & 15049 \\
\hline 1985 & 15163 & 16000 & 15024 & 15949 \\
\hline 1986 & 15984 & 16000 & 15883 & 16082 \\
\hline 1987 & 16859 & 16000 & 17079 & 17120 \\
\hline 1988 & 18150 & 17500 & 17991 & 17963 \\
\hline 1989 & 18970 & 19000 & 18802 & 18743 \\
\hline 1990 & 19328 & 19000 & 18994 & 19163 \\
\hline 1991 & 19337 & 19500 & 18994 & 19163 \\
\hline 1992 & 18876 & 19000 & 18916 & 18743 \\
\hline MSE & - & 86694 & 41426 & 22717 \\
\hline
\end{tabular}

\section{REFERENCES}

[1] Q. Song, B.S. Chissom, "Forecasting enrollments with fuzzy time series-Part I", Fuzzy Sets and Systems, 54 (1993b) 1-10.

[2] Q. Song, B.S. Chissom, "Forecasting enrollments with fuzzy time series-Part II", Fuzzy Sets and Systems, 62 (1994) $1-8$
[3] S. M. Chen, "Forecasting enrollments based on fuzzy time series", Fuzzy Sets and Systems, 81 (1996) 311-319.

[4] J. R. H Wang, S. M. Chen, C. H. Lee, ":Handing forecasting problems using fuzzy time series", Fuzzy Sets and Systems, 100 (1998) 217-228.

[5] K. Huarng, "Heuristic models of fuzzy time series for forecasting", Fuzzy Sets and Systems, 123 (2001) 369386.

[6] T. A. Jilani, S. M. A. Burney, C. Ardil, “ Fuzzy metric approach for fuzzy time series forecasting based on frequency density based partitioning", In: Proceedings of World Academy of Science, Engineering and Technology 23 (2009) 1307-6884. 